\title{
New data on Soricimyxum fegati (Myxozoa) including analysis of its phylogenetic position inferred from the SSU rRNA gene sequence
}

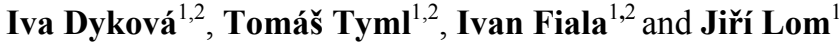 \\ ${ }^{1}$ Institute of Parasitology, Biology Centre, Academy of Sciences of the Czech Republic, Branišovská 31, 37005 České \\ Budějovice, Czech Republic; \\ ${ }^{2}$ Faculty of Science, University of South Bohemia, Branišovská 31, 37005 České Budějovice, Czech Republic
}

Key words: Myxozoa, Soricimyxum fegati, SSU rDNA phylogeny, Sorex araneus, Soricomorpha

\begin{abstract}
A myxosporean species found to develop in the liver of 10 out of 24 common shrews, Sorex araneus L., caught in South Bohemia, Czech Republic, was identified as Soricimyxum fegati Prunescu, Prunescu, Pucek et Lom, 2007, the unique representative of the genus and the first myxosporean species known to develop from plasmodia to spores in a terrestrial mammal. The original description of this species, based on fixed material, is supplemented with new data based on fresh material and with partial sequence of SSU rDNA (GenBank Acc. No. EU232760). Phylogenetic analysis of SSU rDNA revealed that $S$. fegati is closely related to myxosporeans infecting gall bladders of freshwater fish.
\end{abstract}

The recent paper of Prunescu et al. (2007) describing a surprising case of myxosporosis in shrews (Sorex araneus) caught in Bialowieza primeval forest, Poland, has prompted us to examine shrews in South Bohemia for the presence of the same myxosporean, Soricimyxum fegati Prunescu, Prunescu, Pucek et Lom, 2007 in the Czech Republic. Our effort has been crowned with success and here we report on some additional observations on the parasite's morphology, infection of hosts and a phylogenetic analysis of the SSU rDNA.

\section{MATERIALS AND METHODS}

This study was done in August and September 2007 when shrews were collected for a population genetic study by another research team in three localities approximately $10 \mathrm{~km}$ south of České Budějovice (South Bohemia, Czech Republic). Disposable plastic jars of a diameter $9.5 \mathrm{~cm}$ and depth $14 \mathrm{~cm}$ were used as stationary, baited pitfall traps. They were checked once (early in the morning) or twice a day. In total, 24 common shrews, Sorex araneus L., 29 pygmy shrews, Sorex minutus L., and 1 water shrew, Neomys fodiens Pennant were caught and examined in this study.

After basic biometric measurements of shrews were taken, individual specimens were dissected and the liver, kidney, spleen, lungs, heart and brain, regardless of their condition, i.e., whether well preserved or with distinct postmortal changes, were sampled for histological examination. Haematoxylin and eosin (H\&E) and Giemsa method $(\mathrm{G})$ were used to stain histological sections.

The liver parenchyma was examined also fresh, using 8-10 preparations of squashed tissue from each shrew. Olympus BX 51 microscope equipped with Nomarski differential interference contrast (DIC) was used for examination and Olympus DP 70 digital camera for documentation.

Spores were measured fresh. Average values of their length (L) and width (W) as well as diameter of polar capsules (PC) were first calculated for spores of the same origin (from each of five positive specimens of $S$. araneus) and then for the whole dataset $(n=60)$. Additionally, spores found in suitable positions were also measured in histological sections. Spores under study were compared with type material spores of $S$. fegati (histological sections, nos. DFP 012 and 013, deposited in the Institute of Parasitology, Biology Centre AS CR, České Budějovice).

Small samples of fresh liver tissue of nine $S$. araneus and two S. minutus were used for isolation of DNA from the myxosporean under study. SSU rRNA gene was amplified by nested PCR using the conditions described elsewhere (Fiala 2006). The initial PCR was performed using universal eukaryotic primers ERIB1 and ERIB10 (Barta et al. 1997). Myxosporean specific primers MyxospecF and MyxospecR (Fiala 2006) were used for the following PCR. In order to obtain complete SSU rDNA sequence, additional PCRs were done with following primers: ERIB1 + ACT1R (Hallet and Diamant 2001) and MYXGEN4f (Kent et al. 2000) + ERIB10. The amplicons of three samples were isolated from 1.0\% agarose gels and cloned into the pDrive Cloning Vector using QIAGEN PCR Cloning Kit (QIAGEN GmbH, Hilden, Germany). Both strands were sequenced on an automated sequencer ABI 3130xl using the BigDye ${ }^{\circledR}$ Terminator v3.1 Cycle Sequencing Kit (Applied Biosystems, Foster City, CA).

The longest SSU rRNA gene sequence of the myxosporean under study was aligned with closely related sequences of freshwater species branching within the so-called gall bladder clade (GB in Fiala 2006) using the Clustal_X program (Thomson et al. 1997). The sequence of Chloromyxum leydigi was used as outgroup. Alignment was refined by eye using the BioEdit sequence alignment editor (Hall 1999). Trees were constructed using the maximum likelihood (ML) and maximum parsimony (MP) methods, carried out using the program package PAUP*, version 4.0b10 (Swofford 2001). The MP analysis was done using heuristic search with random addition of taxa (10 replications) and gaps were treated as missing data. 
Transitions/transversions (Ts/Tv) ratio was 1:2. For the ML analysis, the likelihood ratio test (LRT) implemented in the Modeltest; version 3.06 (Posada and Crandall 1998) was used to determine the best model of evolution. ML was performed with the GTR $+\Gamma+\mathrm{I}$ model. Clade support was assessed with bootstrapping (500 bootstrap replicates for ML and 1,000 bootstrap replicates for MP, respectively).

\section{RESULTS}

Of the examined shrews, only $S$. araneus was found to be infected with myxosporeans (Figs. 1-11). Myxospores resembling those of $S$. fegati were found in squash preparations of the liver parenchyma in 10 out of 24 S. araneus. In fresh preparations, the shape of mature spores and the shape and position of polar capsules (PCs) were the same as previously described for $S$. fegati (Figs. 3-6). Thick-walled ovoid spores were 12.3 (11.7-12.9) $\mu \mathrm{m}$ long and $9.4(8.8-10.0) \mu \mathrm{m}$ wide (the mean with range in parentheses; $n=60)$. Spore thickness could not be measured safely in fresh material due to the almost invariably frontal position of spores in squash preparations. The diameter of two equal PCs situated one at each pole of the spore was $3.5 \mu \mathrm{m}$ re- gardless of position of mature spores in squashed tissues. Two coils of polar filament were seen in most PCs (Figs. 2, 5). Fine longitudinal ridges seen on the surface of spore valves were difficult to document (Fig. 6) but they were relatively easy to observe when changing the microscope focus.

Clearly delimited, finely granular multicellular plasmodial stages, containing mature spores, were observed in intrahepatic bile ducts (Fig. 1). Pansporoblasts (Fig. 2) were observed frequently. The size of fixed spores measured in histological sections prepared from our material as well as in $S$. fegati type material was found almost identical, being $11.0-12.0 \mu \mathrm{m}$ in length and 7.7$8.3 \mu \mathrm{m}$ in width.

When examined in fresh squashed material, plasmodial stages and myxospores were found in no organ other than liver. By the number of plasmodia and mature spores, there were only slight differences in intensities of infections. In 10 pieces of liver tissue examined per host individual, a maximum of 20 developed spores were found in a host specimen.

Histological examination of organs of 24 common shrews confirmed the presence of the myxosporean in
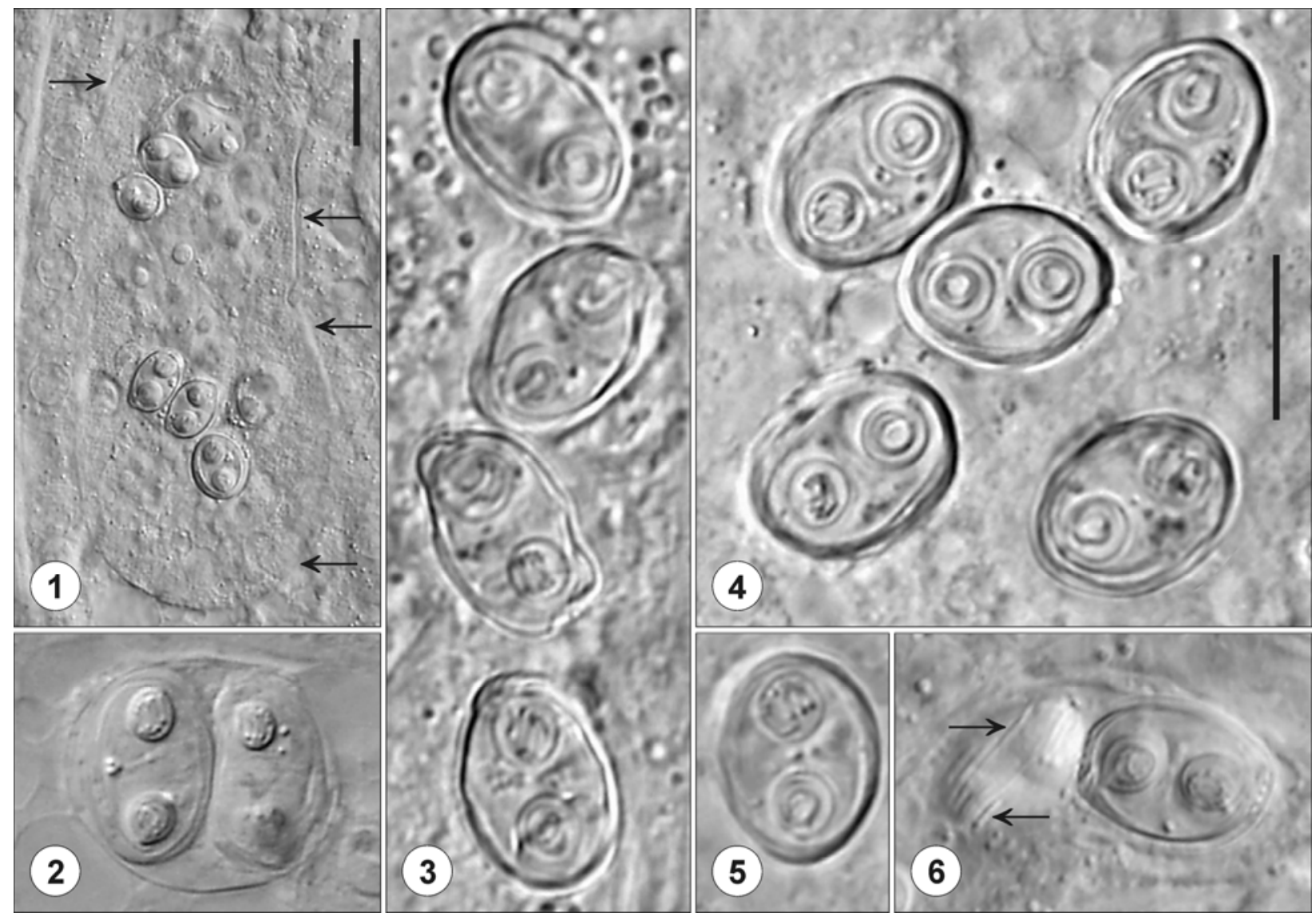

Figs. 1-6. Soricimyxum fegati as observed in fresh (squash preparations of the liver tissue of Sorex araneus; DIC). Fig. 1. Plasmodium with mature spores located in the biliary duct. Delimitation of the plasmodium is marked with arrows. Fig. 2. Two spores developing in pansporoblast. Figs. 3-5. Mature spores as observed in slightly different positions. Fig. 6. An appropriate focus reveals ridges on the valve surface of one spore. Scale bars: Fig. $1=20 \mu \mathrm{m}$; Figs. $2-6$ (same scale) $=10 \mu \mathrm{m}$. 


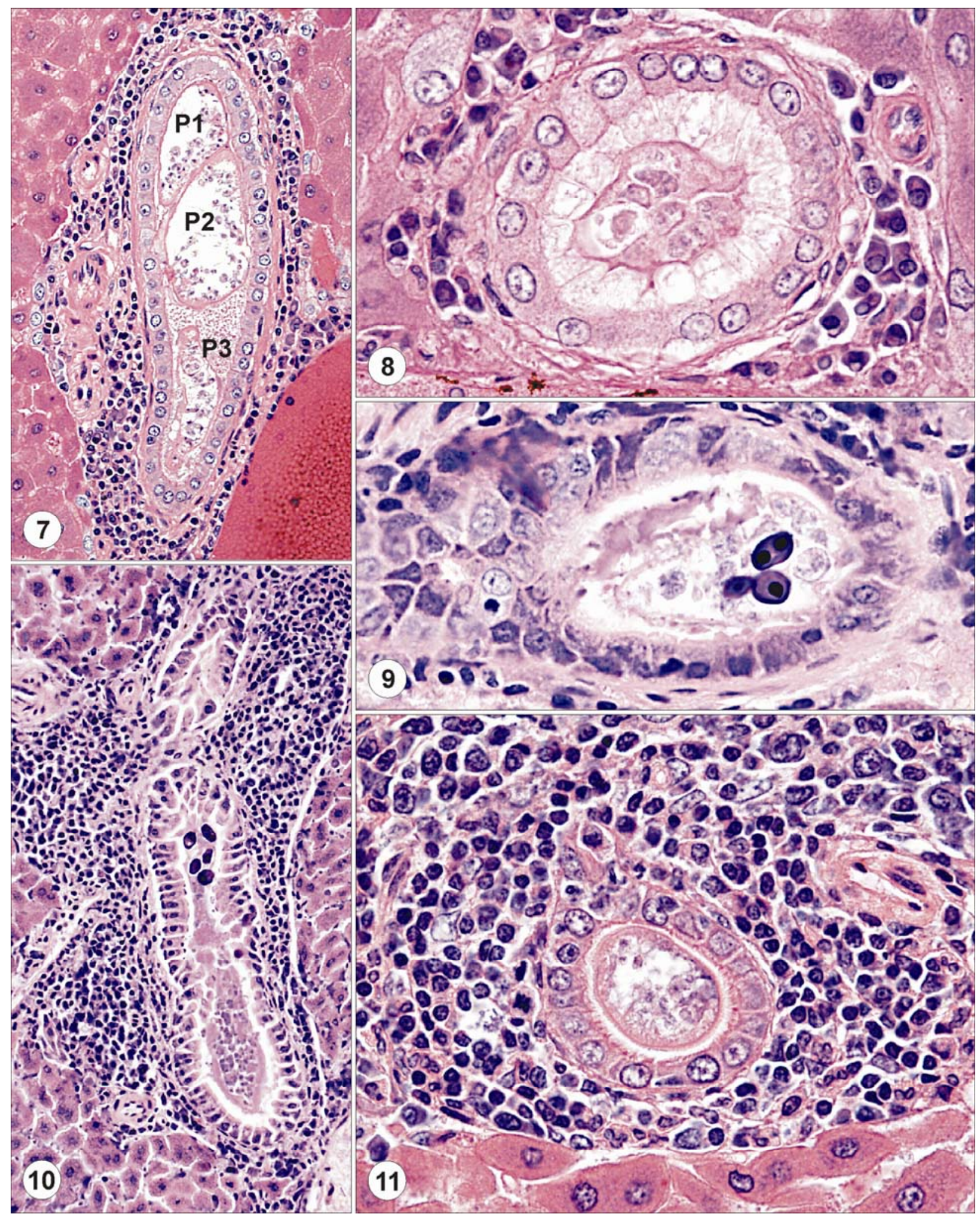

Figs. 7-11. Histopathological changes in Soricimyxum fegati infections in Sorex araneus. Figs. 7, 8. Histological sections through biliary ducts with plasmodial stages of $S$. fegati. H\&E, $\times 295$ and $\times 740$, respectively. Host reactions surrounding biliary ducts are in early stages of their development. Since the section shown in Fig. 7 is rather longitudinal, P1-P3 might represent either three plasmodia or three parts of the same, long and twisted plasmodium. Fig. 9. Mature spores with densely stained polar capsules in the lumen of a biliary duct. Giemsa, $\times 740$. Fig. 10. Overview of advanced host response around a biliary duct containing plasmodium and mature spores. Giemsa, $\times 280$. Fig. 11. Agglomeration of monocytic cells around a biliary duct with plasmodium of S. fegati. H\&E, $\times 740$. 
the liver only. Although intensity of the myxosporean infection proved to be low in all shrews, histological examination raised the number of positive shrews to 10 . Histopathological changes related to the presence of myxosporean under study were observed in the intrahepatic biliary system (Figs. 7-11). The biliary ducts containing plasmodia were surrounded by infiltrating cells in a circular manner (Figs. 10, 11). Although cuffings of infiltrating cells differed in diameters, their composition was uniform. Lymphocytes prevailed in mononuclear infiltrate and usually were accompanied with monocytes. Leucocytes were found exceptionally, in only one shrew in which the liver parenchyma was destroyed by migration channels of nematodes. Semiserial sections revealed that the host reaction accompanied long segments of bile ducts and was observed even when plasmodial stages were absent at the level of sectioning. The extent of damage of epithelial lining of bile ducts was difficult to evaluate. The interpretation of alterations of epithelium as well as conclusive statement about the development of spores in epithelial lining was complicated due to delayed fixation and postmortal changes. All positive shrews were adult specimens.

Morphology of spores and vegetative stages as well as type of host tissue alterations convinced us that common shrews caught in South Bohemia were infected with S. fegati.

Of other parasites, adult undetermined nematodes were found in the stomach of two shrews, and undetermined larval stages and adult nematodes, together with conglomerates of eggs of Capillaria sp., in the liver of six shrews. Hundreds of Capillaria sp. eggs were found in squash preparations of spleen in four specimens.

The PCR products obtained from 11 samples of DNA were visualised on an agarose gel as 9 bright bends of an expected size (about 950bp) that demonstrated positivity for myxosporeans in 9 common shrews, while two samples from S. minutus were negative. In 8 out of 9 PCR positive common shrews, the spores were found in squash preparations.

The partial SSU rDNA sequences of the myxosporean species under study were obtained from samples of three shrews. The sequence of maximum length $(1,584$ bp) that is deposited in the GenBank database under Acc. No. EU232760 has incomplete 5' end due to failure of PCR amplification with ERIB1 and ACT1R primers. The length of other two partial SSU rDNA sequences obtained from cloned PCR products was 937 bp. In corresponding segments, the similarity of three partial SSU rDNA sequences ranged from 99.15 to $99.25 \%$.

The phylogenetic analysis of SSU rDNA revealed $S$. fegati to be closely related to the myxosporeans infecting the gall bladder of freshwater fish (the freshwater GB clade as described in Fiala 2006). The strong position of $S$. fegati in this clade is supported by relatively high bootstrap values ( $76 \%$ in ML and $100 \%$ in MP).

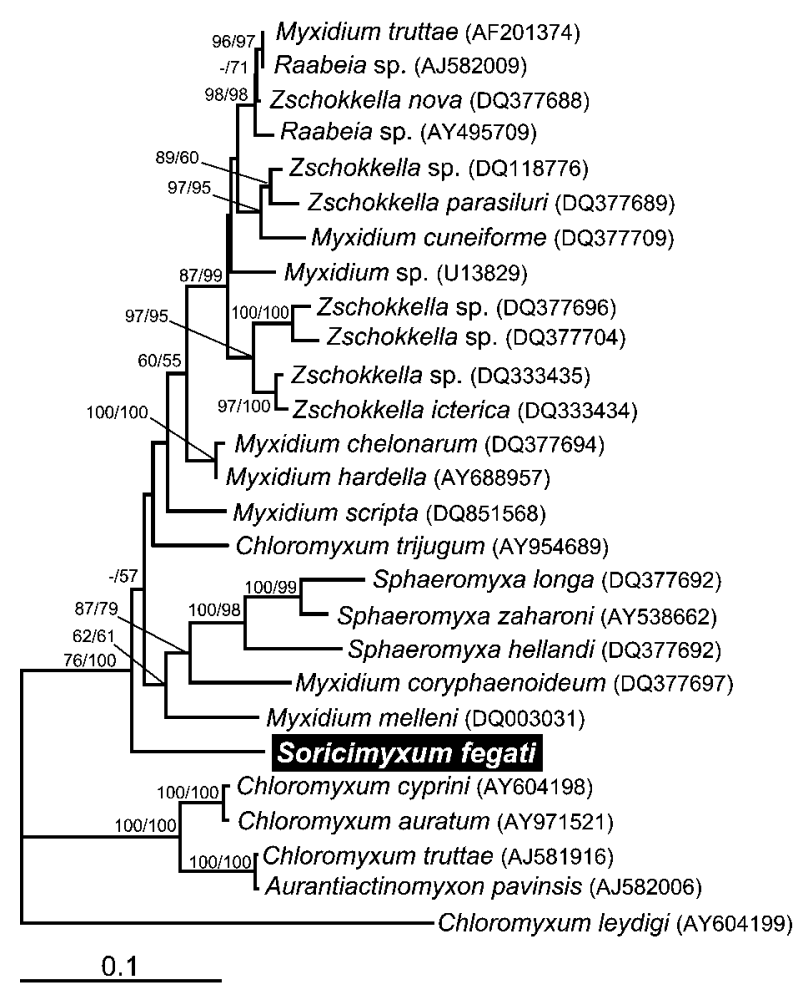

Fig. 12. SSU rDNA tree (ML analysis, $-\ln =7604.2018$ ) showing the phylogenetic position of Soricimyxum fegati relative to myxosporeans from the freshwater GB clade (after Fiala 2006). The numbers at the nodes are bootstrap percentages (ML/MP) above $50 \%$. The scale bar is given under the tree. GenBank accession numbers are in parentheses.

Phylogenetic tree (Fig. 12) shows the result of ML analysis, with the basal position of $S$. fegati to all Zschokkella, Myxidium and Sphaeromyxa sequences in the freshwater GB clade. The MP analysis supports this tree topology but the values of both ML and MP bootstrap analyses are very low at the particular nodes.

\section{DISCUSSION}

Originally, we had some doubts about the identity of the myxosporean under study as the measurements of fixed spores reported by Prunescu et al. (2007) were much smaller than those of spores in our histological sections. However, new measurements of spores in the type vouchers proved that the size of spores was bigger than that reported in the original description of $S$. fegati (Prunescu et al. 2007), consistent with the size of our spores. The observation of more full turns of the polar filament in our fresh- than in the type material is easy to explain, since in fixed and stained spores the filament is difficult to detect. Similarly, pansporoblasts were easy to observe in our fresh material, although in the original description of $S$. fegati they were claimed to be absent. Until the sequence of $S$. fegati from Bialowieza is available for comparison, we consider the myxosporeans 
from shrews from Poland and South Bohemia to belong to the same species, S. fegati. We ascribe the noted differences to the fact that the original description from Poland was based on fixed material.

Despite examination of a number of Sorex minutus (29 individuals examined in fresh, 12 histologically, 2 by PCR), $S$. fegati was not found in the samples. This suggests that $S$. fegati is host specific.

The early phase of myxosporean infection of the shrews that was characterized by low number of mature spores in the plasmodial stages, led us to perform a nested PCR using DNA isolated from liver tissue with predominating early plasmodial stages and specific myxosporean primers MyxospecF and MyxospecR. Specificity of the PCR method was clearly proved when annealing temperature was set to $60^{\circ} \mathrm{C}$. Quick and sensitive PCR method seems to give the chance to trace the whole myxosporean phase of life cycle, i.e., even before it might be detected by the light microscopical examination.

Soricimyxum is, to a certain extent, morphologically similar to the representatives of Zschokkella/Myxidium complex (Lom and Dyková 2006). It was erected as a separate genus because of the great distance of its host as regards both its taxonomic position and ecology. In terrestrial habitats, where contact with water environment is rather limited, transmission might take place by peroral infection of both the myxospore and actinospore phase (if existence of the latter can be confirmed at all). Nevertheless, both morphological and SSU rDNA sequence similarities leave open an obvious speculation: this mammalian parasite may have had its origin in the ancestors of one of the several known groups of fish and amphibian/reptile/bird Zschokkella/Myxidium complex. More light may be thrown on the relations of $S$. fegati with the two latter genera, already now presenting themselves a morphological/molecular puzzle, after more sequences of Zschokkella/Myxidium species from amphibians, reptiles and birds have been obtained.

Acknowledgements. We thank the team working on population genetic parameters of Sorex araneus in the context of natural and anthropogenic barriers, represented by J. Zima Jr., Faculty of Science, University of South Bohemia, for providing shrews for this study. The study was financially supported by the Ministry of Education, Youth and Sports of the Czech Republic (project MSM6007665801), the Research Centre "Ichthyoparasitology" (LC522) and the research project of the Institute of Parasitology, Biology Centre, Academy of Sciences of the Czech Republic (Z60220518).

\section{REFERENCES}

Barta J.R., Martin D.S., Liberator P.A., DashkeVicz M. Anderson J.W., Feighner S.D., Elbrecht A., PerkinsBARROW A., JENKINS M.C., DANFORTH H.D., RUFF M.D., Profous-JUCHELKA H. 1997: Phylogenetic relationships among eight Eimeria species infecting domestic fowl inferred using complete small subunit ribosomal DNA sequences. J. Parasitol. 83: 262-271.

FIALA I. 2006: The phylogeny of Myxosporea (Myxozoa) based on small subunit ribosomal RNA gene analysis. Int. J. Parasitol. 36: $1521-1534$.

HALL T.A. 1999: BioEdit: a user-friendly biological sequence alignment editor and analysis program for Windows 95/98/NT. Nucl. Acids Symp. 41: 95-98.

HALLET S.L., DiAMANT A. 2001: Ultrastructure and small-subunit ribosomal DNA sequence of Henneguya lesteri n. sp. (Myxosporea), a parasite of sand whiting Sillago analis (Sillaginidae) from the coast of Queensland, Australia. Dis. Aquat. Org. 46: 197-212.

Kent M.L., Khattra J., Hedrick R.P., DeVlin R.H. 2000: Tetracapsula renicola n. sp. (Myxozoa: Saccosporidae); the
PKX myxozoan - the cause of proliferative kidney disease of salmonid fishes. J. Parasitol. 86: 103-111.

LOM J., DYKOVÁ I. 2006: Myxozoan genera: definition and notes on taxonomy, life-cycle terminology and pathogenic species. Folia Parasitol. 53: 1-36.

Posada D., Crandall K.A. 1998: Modeltest: testing the model of DNA substitution. Bioinformatics 14: 817-818.

PRUNESCU C.-C., PRUNESCU P., PUCEK Z., LOM J. 2007: The first finding of myxosporean development from plasmodia to spores in terrestrial mammals: Soricimyxum fegati gen. et $\mathrm{sp}$ n. (Myxozoa) from Sorex araneus (Soricomorpha). Folia Parasitol. 54: 159-164.

SWOFFORD D.L. 2001: PAUP*: Phylogenetic Analysis Using Parsimony, Version 4.0b10. Sinauer Associates, Sunderland, MA.

ThOMPSON J.D., Gibson T.J., Plewniak F., Jeanmougin F., HIGGINS D.G. 1997: The CLUSTAL_X windows interface: flexible strategies for multiple sequence alignment aided by quality analysis tools. Nucl. Acids Res. 25: 4876-4882. 